\title{
Development and Design of a High Performance Traction Machine for the FreedomCar 2020 Traction Machine Targets
}

\author{
Adam Walker, Michael Galea, David Gerada, Chris Gerada, Abdeslam Mebarki, Neil Brown
}

\begin{abstract}
This paper details the design process of a high performance electrical machine with the objective of achieving US Department of Energy FreedomCar 2020 targets, namely meeting the high speed efficiency requirement without sacrificing performance elsewhere. The FreedomCar targets are detailed, with a short discussion of the challenges involved. All feasible machine topologies are considered, and qualitatively compared in order to identify the best candidate topologies. A set of potential technologies and topologies are evaluated to establish the primary geometry specifications, such as slot pole combination, winding layout and active length. Optimisation methods are then implemented to establish the more detailed geometrical parameters, e.g. tooth width and slot depth. Finally a conclusive design is presented with the finite element simulation results. The design meets all the performance requirements of the targets.
\end{abstract}

Index Terms - Design optimisation, Electric Vehicles, Permanent Magnet Motors, Traction Motors

\section{INTRODUCTION}

A $\mathrm{S}$ performance requirements become ever more A challenging, there is a constant push towards improvement of electrical machines for traction applications. With hybrid and fully electric vehicles (EV) becoming more popular as passenger vehicles there is a need for a standardisation of products, whilst ensuring high performance for a low cost. The main goal of this constant development is to improve traction machines to a point at which their implementation in EVs becomes a feasible arrangement to combine and/or replace the more traditional internal combustion engine (ICE). To keep hybrid electric vehicles (HEV) competitive in cost and performance to their ICE counterparts, the traction motor must have a high efficiency across the whole speed range (to minimise the battery usage), a good power to weight ratio and be as low cost as possible. To achieve this ambition the US Department of Energy (DoE) has set the extremely challenging, FreedomCar 2020 targets for electrical machines used for HEV traction applications.

Several studies exist, both academic and industrial, aimed at achieving these electrical machine targets [1-4], however a full detailed design process is not present in the available literature. Thus, the aim of this paper is to provide a comprehensive study, starting from a wide range of machine

This work was sponsored by the EPSRC

A. Walker, M. Galea, D. Gerada and C. Gerada are all with the Power Electronics, Machines and Control (PEMC) group, University of Nottingham, Nottingham, UK (e-mail: Adam.Walker@nottingham.ac.uk, Michael.Galea@nottingham.ac.uk,

Chris.Gerada@nottingham.ac.uk).

N. Brown is with Cummins Generator Technologies, Stamford, UK (email: neil.1.brown@cummins.com). A. Mebarki was with Cummins Generator Technologies, Stamford, UK. ideas and narrowing down to a final detailed design, aimed at achieving the DoE FreedomCar 2020 targets.

\section{BACKGROUND}

The DoE is a cabinet level department of the US government, who has set the FreedomCar 2020 targets for the electrical motors used for providing traction in plug-in hybrid electric vehicles (PHEV), to be achieved by the year 2020 .

The main aim of these targets is to push the boundaries of current technology for traction motor drives and electrical machines in general.

A selection of the more critical targets are shown in Table I, while Fig. 1 shows the required rated torque across the speed range, peak torque value and the efficiency requirements.

TABLE I

SUMMARY OF DOE FREEDOMCAR 2020 TARGETS [5]

\begin{tabular}{|l|l|}
\hline Rated Power & $30 \mathrm{~kW}$ \\
\hline Peak Power & $55 \mathrm{~kW}$ for $18 \mathrm{sec}$. \\
\hline Peak Torque & $200 \mathrm{Nm}$ for $18 \mathrm{sec}$. \\
\hline Rated Speed & $2800 \mathrm{rpm}$ \\
\hline Maximum Speed & $14000 \mathrm{rpm}$ \\
\hline DC Link Voltage & $200-450 \mathrm{~V}(325 \mathrm{~V}$ rated $)$ \\
\hline Max Back EMF at Max Speed & $600 \mathrm{~V}$ \\
\hline Maximum Current & $400 \mathrm{~A}$ \\
\hline Maximum Machine Diameter & $250 \mathrm{~mm}$ \\
\hline Maximum Machine Length & $200 \mathrm{~mm}$ \\
\hline Machine Volume & $<9.7 \mathrm{~L}$ \\
\hline Machine Mass & $<35 \mathrm{~kg}$ \\
\hline Maximum coolant temperature & $<105 \mathrm{C}$, Liquid cooled \\
\hline Minimum Peak Efficiency & $>95 \%$ for $10 \%-100 \%$ speed \\
\hline Unit cost & $\$ 275$ per unit, in quantities of \\
& 100,000 \\
\hline
\end{tabular}

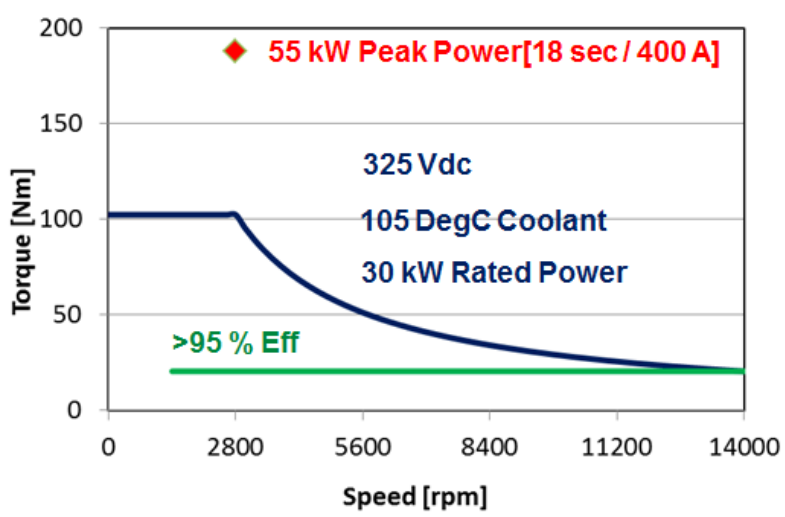

Fig. 1 - Torque speed characteristic of the DoE FreedomCar 2020 targets

From the literature review and the comparative studies presented in this work, it is clear that the main challenges with the machine design are the set high efficiency (which has to be maintained from $10 \%$ to $100 \%$ of the speed range) 
and the associated cost (especially considering the financial effort required when using rare earth PMs) $[1,2,6]$

While it is important to meet the targets over the whole speed range, the two operating points, which are the most challenging (in terms of maintaining the set current, voltage and temperature limits) are the maximum speed (14000 $\mathrm{rpm}, 20 \mathrm{Nm})$ and the peak torque $(2800 \mathrm{rpm}, 200 \mathrm{Nm})$ conditions.

\section{TOPOLOGY SELECTION}

In order to identify the most suited machine technology and topology, relative qualitative indices (QI) as explained in [7] were set and applied to each technology. From the extended literature review in [7], the most appropriate machine configurations are highlighted here.

Table II compares the manufacturability of the machines for this specific application and tabulates the mentioned QIs by setting a score (with 10 being the maximum) for the 6 key factors that define the production and manufacturing of the machine, along with a weighted total.

When assigning the QI values, a higher value is always superior i.e. even for volume and mass, a high value refers to a smaller machine (or a higher power/torque density). Some of the machine topologies here cover a small range, such as the flux switching (FS) topology referring to both PM and wound field configurations, in this case an average value between the two types of FS were used.

A weighting system has been incorporated to the total to represent which factors are more critical to the comparison. Cost was seen as the most critical QI, and was therefore given a weighting of 3 . Volume and mass were the next most important, as keeping these low is crucial in HEV applications, and so their weighting is 2 . The other three QIs were given a value of 1 , as they are still significant, but not of the same 'weight' as cost, volume and mass.

\section{TABLE II}

QI SCORES SHOWING MANUFACTURABILITY OF MACHINE TOPOLOGIES

\begin{tabular}{|c|c|c|c|c|c|c|c|}
\hline Motor Type & 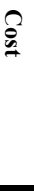 & 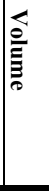 & 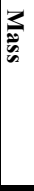 & 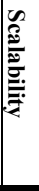 & 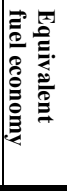 & 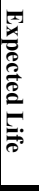 & 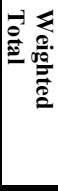 \\
\hline Surface Mount PM & 5 & 9 & 8 & 8 & 9 & 7 & 73 \\
\hline Interior PM & 6 & 9 & 9 & 8 & 9 & 7 & 78 \\
\hline Induction Machine & 8 & 7 & 7 & 8 & 6 & 7 & 73 \\
\hline Switched Reluctance & 10 & 3 & 4 & 7 & 4 & 7 & 62 \\
\hline Synchronous Reluctance & 9 & 5 & 6 & 8 & 7 & 7 & 71 \\
\hline Flux Switching & 7 & 6 & 7 & 7 & 5 & 7 & 66 \\
\hline Flux Memory & 5 & 5 & 4 & 4 & 7 & 4 & 48 \\
\hline Homopolar & 8 & 5 & 6 & 7 & 7 & 7 & 67 \\
\hline Axial Flux & 5 & 9 & 8 & 4 & 9 & 6 & 68 \\
\hline Transverse Flux & 5 & 9 & 8 & 3 & 8 & 6 & 66 \\
\hline Double Stator PM & 4 & 10 & 7 & 6 & 10 & 6 & 68 \\
\hline
\end{tabular}

From Table II, it is clear that the best performance is achieved by the interior permanent magnet (IPM) machine, closely followed by the surface mount permanent magnet (SMPM) technology. The IM has a high total but to meet the same torque as an IPM machine, it would require a larger volume. The double stator and the alternative flux direction, axial and transverse, machines also perform well but these have significant draw backs, such as design complexity, cost and poor scalability, which imply the general superiority of the IPM configuration.
The performance of these machines has been compared, including their perceived potential, from available literature such as [7-12], to reach the peak torque and the speed range that high efficiency could be maintained for. This information is represented graphically in Fig. 2, which gives the area on a generic torque speed characteristic where each topology produces the optimum performance. The colours used here represent the PM mass requirement, with red being high, yellow indicating a small (or optional) PM material amount and green showing that no PMs are required.

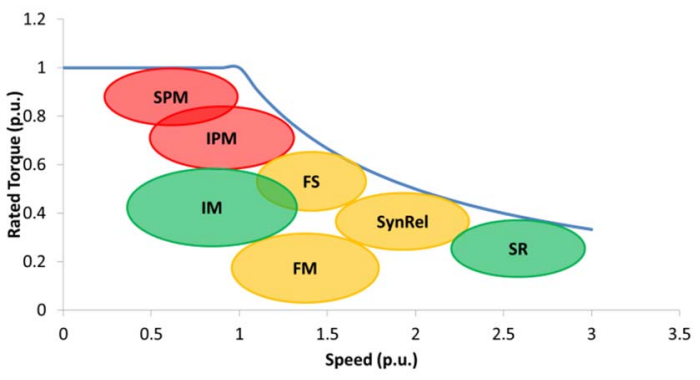

Fig. 2 - Optimum operating aspects for the range of machine topologies

From Fig. 2, it can be observed how the SMPM and IPM technologies achieve better torque density performances, but do not perform as well in the extended speed range. As can be expected, the SR machine has a low torque density but very high speed capabilities. The remaining technologies give varying results between these two extremes with some positives and some negatives, when considered for the application at hand, covered in [7].

As is clear from the QI scores, the interior permanent magnet (IPM) machine appears to be the best choice to use for the FreedomCar 2020 targets. A consideration towards adding more reluctance to the design, i.e. moving towards a permanent magnet assisted synchronous reluctance (PMaSynRel) topology is also made to ensure meeting the high speed performance requirements.

\section{DESIGN REFINEMENT}

The next step in the design process is an investigation on the winding type to be used, concentrated or distributed, in parallel with considerations for the optimal slot pole combination. Because of the nature of this application, where both high torque density and high speed requirements are vital, it was decided to consider both winding options in the design process. Further details of this study are given in [13]

\section{A. Slot Pole Combination Range}

An array of different slot pole combinations were considered for both winding layouts, 28 designs for concentrated and 13 for distributed with the pole numbers considered, ranging from 4 to 12 . Initially analytical models were used to rapidly simulate the wide choice of designs, as the range narrowed finite element analysis was implemented to increase the simulation accuracy and confidence in the results.

For both winding layouts an optimum slot number for each pole amount was found, based on its ability to meet the FreedomCar targets, such as having the highest efficiency and lowest current requirement. With their optimal slot number, each pole number was then compared based on similar requirements. 10 poles gave the best trade-off between torque density and frequency for both winding 
layouts. The best combinations found for each winding method were a 12 slot 10 pole concentrated wound machine, and 30 slot 10 pole distributed wound [13].

\section{B. Concentrated vs Distributed Design Comparison}

The comparison of the final two machines, based on the DoE 2020 targets, is given in Table III. For clarity and visualization purposes, a tick $(\checkmark)$ is used to indicate that the target has been met by this design. A dash (-) shows that the target was not met or barely met, but could be achieved through small design improvements. Crosses $(\mathbf{x})$ indicate that the target has not been achieved and is unlikely to be met even with extensive modifications to the design.

TABLE III

CONCENTRATED VS. DISTRIBUTED IPM DESIGNS COMPARED TO FREEDOMCAR 2020 TARGETS

\begin{tabular}{|c|l|l|l|l|}
\hline Requirements & \multicolumn{2}{|c|}{$\begin{array}{c}\text { Concentrated } \\
\text { Design }\end{array}$} & \multicolumn{2}{c|}{$\begin{array}{c}\text { Distributed } \\
\text { Design }\end{array}$} \\
\hline Rated Power (kW) & 29.9 & $\checkmark$ & 30.0 & $\checkmark$ \\
\hline Peak Power (kW) & 58.7 & $\checkmark$ & 58.6 & $\checkmark$ \\
\hline Peak Torque (Nm) & 200.2 & $\checkmark$ & 200.0 & $\checkmark$ \\
\hline Maximum Current (Arms) & 256.3 & $\checkmark$ & 269.8 & $\checkmark$ \\
\hline DC Link Voltage (V) & 325 & - & 325 & - \\
\hline $\begin{array}{c}\text { Max Back EMF at Max } \\
\text { Speed (V) }\end{array}$ & 608 & - & 571 & $\checkmark$ \\
\hline Winding Temperature ( $\left.{ }^{\circ} \mathrm{C}\right)$ & 166 & $\checkmark$ & 162 & $\checkmark$ \\
\hline $\begin{array}{c}\text { Maximum Machine } \\
\text { Diameter (mm) }\end{array}$ & 250 & $\checkmark$ & 250 & $\checkmark$ \\
\hline $\begin{array}{c}\text { Maximum Machine Length } \\
\text { (mm) }\end{array}$ & 200 & - & 130 & $\checkmark$ \\
\hline $\begin{array}{c}\text { Maximum Machine } \\
\text { Volume (L) }\end{array}$ & 9.7 & $\checkmark$ & 6.38 & $\checkmark$ \\
\hline Mass (kg) & 51.68 & $\mathbf{x}$ & 30.41 & $\checkmark$ \\
\hline $\begin{array}{c}\text { Minimum Peak Efficiency } \\
\text { (\%) }\end{array}$ & 86.4 & $\mathbf{x}$ & 88.0 & $\mathbf{x}$ \\
\hline
\end{tabular}

From Table III, it is clear that both machines can meet the torque across the full speed range with the distributed machine requiring a higher current loading than the concentrated machine to reach the torque requirement. The current was higher in the distributed machine due to the shorter machine length and having a lower turns per phase than the concentrated machine [13]. This was further pronounced at high speed where even more current is needed to perform field weakening. The ensuing extra losses in the distributed machine can be observed in Fig. 3a, which compares the iron loss (combining stator and rotor iron losses) and copper loss (including end winding and ac losses). The efficiency across the speed range is displayed in Fig. 3b, which also accounts for magnet losses, as do the other efficiencies shown in this paper.

Fig. $3 b$ shows that the high speed efficiency is better in the distributed design than the concentrated one. As shown above, the loss components in the two machines differ considerably, however both these machines meet most of the targets. The main challenges remaining are the high speed efficiency and the cost. Considering that the superior efficiency was achieved by the distributed wound design, it was decided that the machine with higher potential to achieve the targets is the 30 slot 10 pole distributed wound IPM.
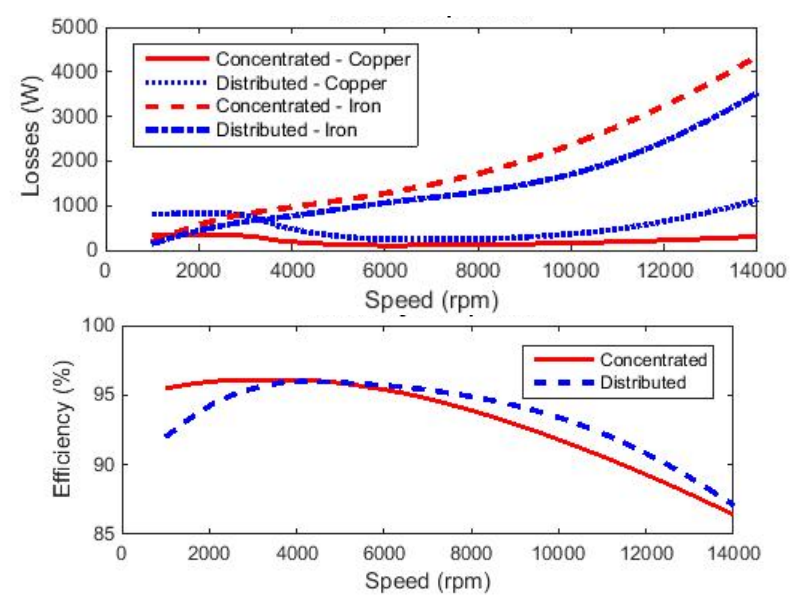

Fig. 3a) Key losses of the concentrated IPM and distributed IPM designs across the speed range. b) Efficiency of the concentrated IPM and distributed IPM designs across the speed range

\section{Improvement on the design}

While it has been shown that the distributed wound machine above is the optimal design for a flat magnet IPM, the motor still requires some improvements to meet some of the targets, most noticeably the high speed efficiency [13]. V-shaped or flux focusing IPMs were also considered, however their increased performance often derives from an increase in PM mass, which is detrimental to keeping the cost minimal.

The challenge with the high speed efficiency is primarily due to iron losses, which can be mitigated by enhancing the reluctance properties of the rotor. This can be achieved by evolving the design into a PMa-SynRel machine, thus increasing the reluctance torque. Other perceived advantages include a decrease of the magnet mass, and current requirement

An initial PMa-SynRel design with the same stator design as the distributed wound machine was created and compared to the IPM design. It was found that while the IPM requires lower current to meet the peak torque at base speed, at maximum speed the PMa-SynRel design requires lower current and ensures a higher efficiency. The current density values for the peak torque are $14.86 \mathrm{~A} / \mathrm{mm}^{2}$ for the IPM and $22.01 \mathrm{~A} / \mathrm{mm}^{2}$ for the PMa-SynRel. For the max speed operating point the current density is $6.95 \mathrm{~A} / \mathrm{mm}^{2}$ in the IPM and $4.5 \mathrm{~A} / \mathrm{mm}^{2}$ in the PMa-SynRel.

From Fig. 4a it can be seen that at high speed the PMaSynRel design has much lower losses (both copper and iron) than the IPM machine. At low speed, while the iron losses are similar between the two designs, the copper losses are much higher in the PMa-SynRel design.

From all the above, it can be safely concluded that if the efficiency of the high speed operating point is the most important aspect of the machine, the PMa-SynRel machine is optimal, while if the critical point is the peak torque performance then the IPM is a better candidate. The major challenge with the FreedomCar 2020 targets, and the aim of this paper, is maintaining the efficiency requirement at high speed, so the PMa-SynRel machine will be focused on in the following sections.

D. Cost Analysis

From a financial perspective, the distributed IPM machine is cheaper to manufacture and produce than the concentrated. The distributed machine requires less PM mass and steel 
mainly due to the shorter length. The PMa-SynRel requires even less PM mass than the distributed wound IPM, significantly reducing the material cost, however the construction of the rotor would be more complex, increasing the manufacturing costs.
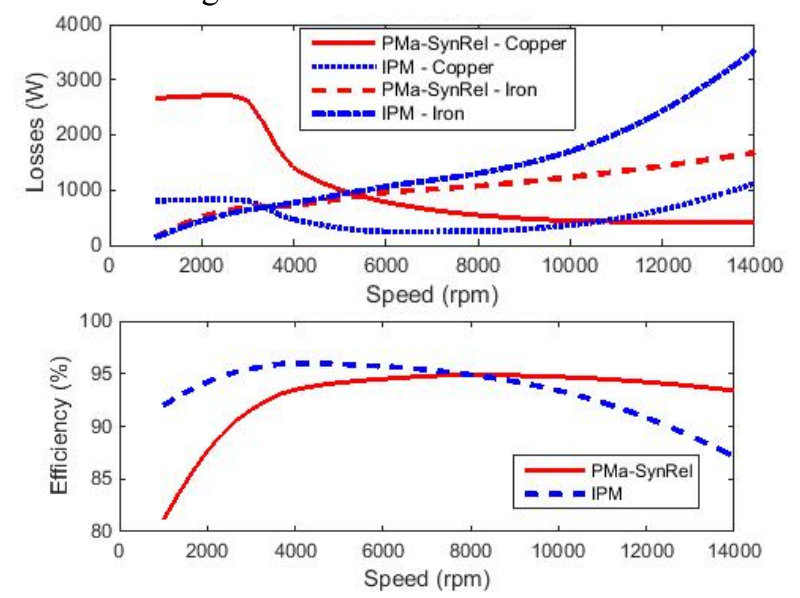

Fig. 4a) Key losses of the distributed IPM and PMa-SynRel designs across the speed range at rated power. b) Efficiency of distributed IPM and PMaSynRel designsacross the speed range at rated power

\section{DESIGN OPTIMISATION}

As a final step towards achieving the best design for the FreedomCar targets, optimisation procedures using genetic algorithms were incorporated into the design process.

A. Maximising reluctance torque

To use the minimal amount of PM mass and obtain the maximum torque per amp, the reluctance torque must be maximised. Reducing the PM mass reduces the material cost of the design significantly. Increasing the torque per amp reduces current requirements, in turn reducing the copper losses, which always play a significant role in respecting the thermal limits of the machine.

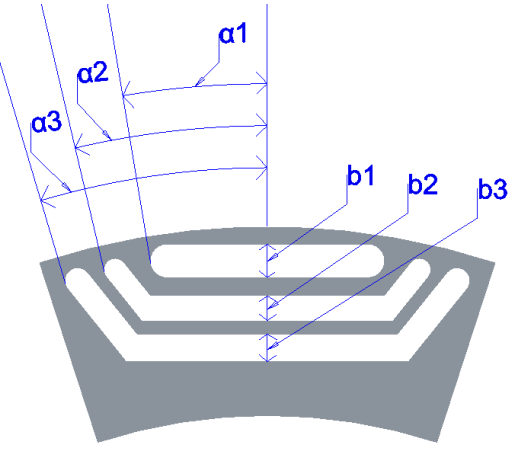

Fig. 5 - Rotor geometry parameters

To achieve this goal, the objective function of the optimisation algorithm was maximisation of torque performance in a rotor with zero PM mass. The considered variables for optimisation are shown in Fig. 5, $\alpha 1$ to $\alpha 3$ are the angles to the tip of each air barrier and b1 to b3 are the thickness of each barrier. This gave 6 parameters to be optimised. In parallel to this, analytical mechanical constraints were implemented to ensure the rotor could withstand the stresses at high speed. Figs. 6 and 7 show the results from this optimisation.
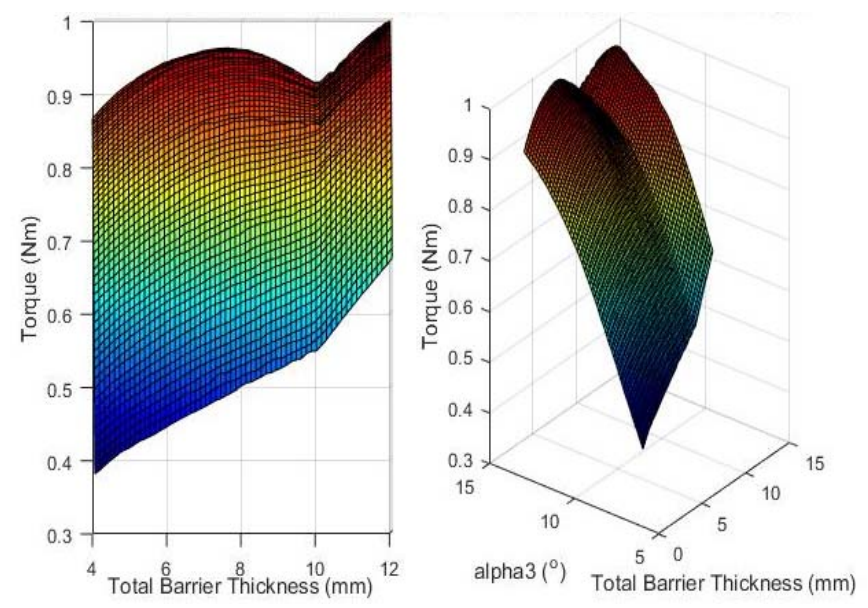

Fig. 6 - Reultance torque based on total barrier angle and cumulative barrier thickness

In Fig. 6 it can be seen that as a general rule the reluctance torque increases with cumulative barrier thickness and total arc span, excluding a small trough that appears at $10 \mathrm{~mm}$ thickness. However when both values are at their maximum geometrical limit, this results in very narrow paths along the rotor 'q-axis', thus saturating the rotor flux paths and reducing the torque, giving a drop in the graph when both of these values are high. The maximum torque here is achieved with the maximum combined barrier thickness, $12 \mathrm{~mm}$ and a total span of $14^{\circ}$.

The combined barrier thickness shown in Fig. 6 had to be distributed between the three air gaps in an optimal ratio. A distinct ridge of maximum torque is presented in Fig. 7, showing a range of ratios that complement one another, with the peak of this being a ratio of $1: 0.5: 0.8(\mathrm{~b} 1: \mathrm{b} 2: \mathrm{b} 3)$.

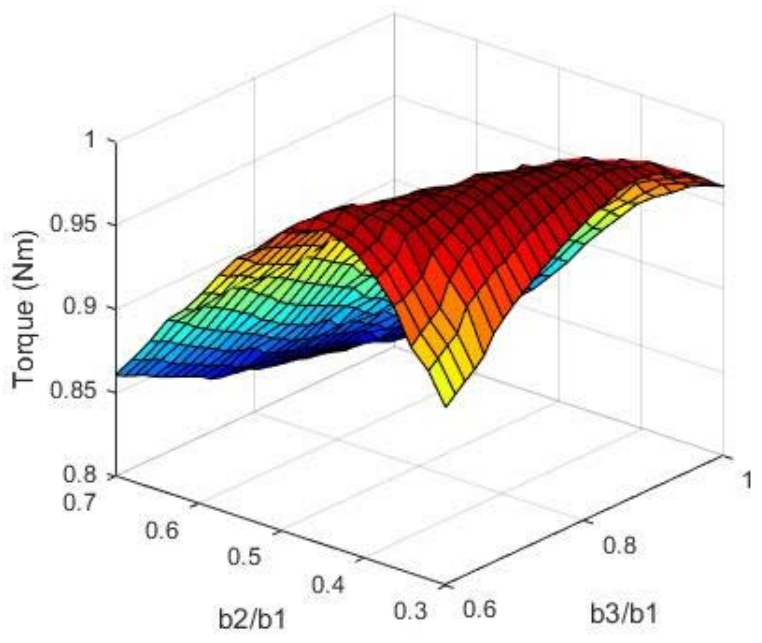

Fig. 7 - Reultance torque based on the distibution of total barrier thickness between the three barriers.

B. Minimising Magnetic Mass

In order to keep the lowest value possible in terms of $\mathrm{NdFeB}$ mass, the PMs were only added to the top barrier in such a manner as to fill the gap in the radial and axial directions as shown in Fig. 8. With this consideration, the optimisation process can be focused on increasing the magnet span until the optimal value of PM mass against current requirements is found. For each magnet span the temperature was compared to the thermal limit of the winding insulation $\left(180^{\circ} \mathrm{C}\right)$ [14]. 


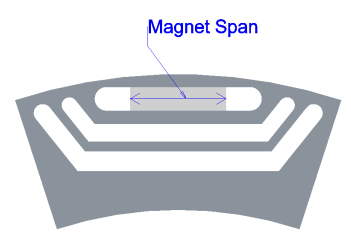

Fig. 8 - Rotor geometry with added PM.

The results from this optimisation are represented in Fig .9, showing that the minimum magnet span percent is within both the current and thermal limit from just below $80 \%$. The greater of these, and thus the more critical, is the current requirement which is within the limit for a magnet span greater than $79 \%$.

\section{Minimising Losses at Key Operating Points}

In order to achieve the optimal efficiency characteristic, a genetic algorithm was used with a more complex objective function. The function minimises the losses at the high speed operating point, until the efficiency is greater than the $95 \%$ target. Once the high speed efficiency has been achieved, the function switches to minimising the losses at the peak torque operating point.

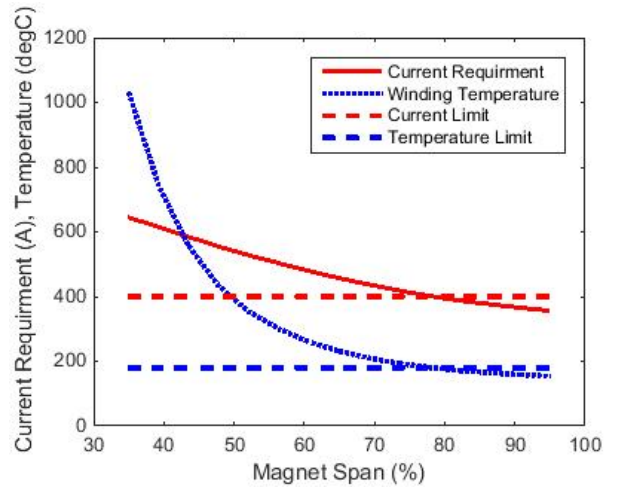

Fig. 9 - Current and winding temperature for the feasible range of magnet spans

The variables for this are based around the tooth and slot shape shown in Fig. 10. A fixed area (one slot pitch) must be shared between each tooth and slot. Larger iron areas give lower iron losses while larger copper areas result in lower the copper losses. Slot width and depth, along with tooth tip shape and yoke thickness were adjusted to balance these losses. Constraints are used to ensure that the required torque values are met; with the VA and thermal limit not exceeded.

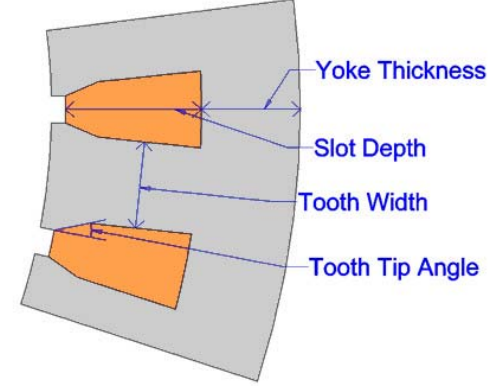

Fig. 10 - Stator geometry parameters

Fig. 11 shows the combined copper and iron losses at high speed for varying values of tooth width and slot depth. The tooth width values in the middle of the range give the best balance between copper and iron losses. At high speeds the iron losses are dominant; this results in Fig. 11 showing that smaller slot depths (larger yokes) gives lower overall losses. However at rated speed, where copper losses are dominant, the opposite would be true, larger slot depths would give lower overall losses. The optimisation process accounted for both of these points, balancing the optimal losses between the two.

\section{FINAL DESIGN}

This section details the final design of the PMa-SynRel machine after the above optimisation process. This traction machine has been developed for achieving the target of the 95\% efficiency at high speed, without sacrificing performance elsewhere on the speed range, in accordance with the FreedomCar 2020 targets.
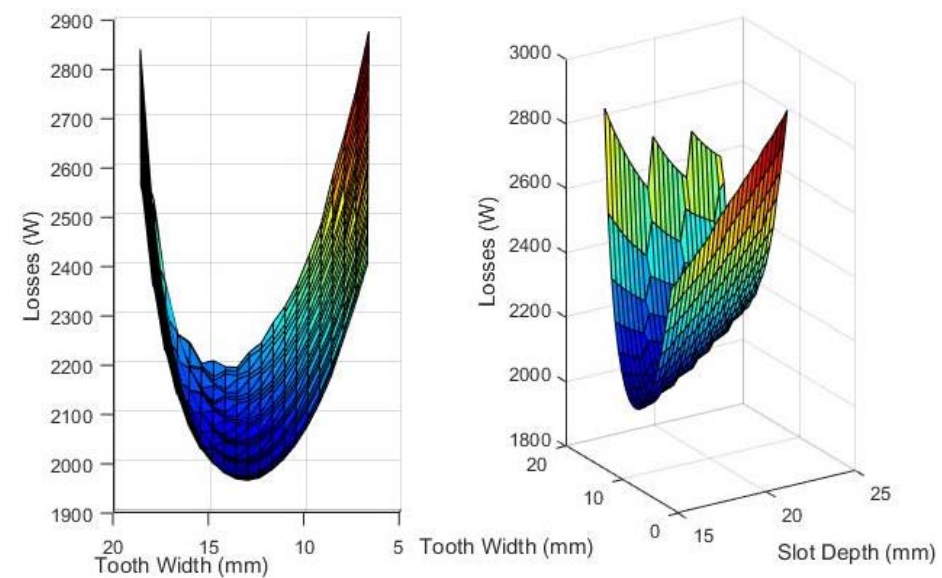

Fig. 11 Combined losses for an array of tooth width and slot depths at the high speed operating point

\section{A. Geometry}

Fig. 12 illustrates the final geometry of the design after the process of optimising the barrier size, magnet mass and stator design.

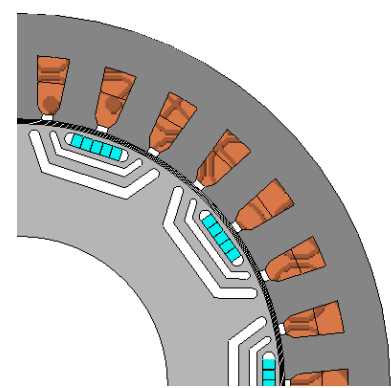

Fig. 12 - Final geomerty of PMa-SynRel design

B. Electro Magnetic Results

This section presents the key performance achievements from FE analysis of the optimised design shown in Fig. 12.

Fig. 13 shows the VA ratings required to produce the torque speed characteristic, thus showing that this characteristic has been achieved, whilst maintaining the current and voltage limits. The crosses show the peak torque produced and the VA rating for this point.

A comparison of the losses achieved from the original PMaSynRel design to those from the final machine (across the whole speed range) is illustrated in Fig. 14. This shows how significant the improvements of the optimisation are, mainly for the low speed range. Using this loss data, a plot highlighting the efficiency across the speed range can be developed, shown in Fig. 15. 
Fig. 15 shows that except at very low speeds the efficiency is above the required $95 \%$. The maximum efficiency is achieved at $6000 \mathrm{rpm}$. From a loss perspective, this can be considered as the 'point of balance' between the higher copper losses at low speed and the higher iron losses at high speeds. The cross shown here is the efficiency at the peak torque operating point.

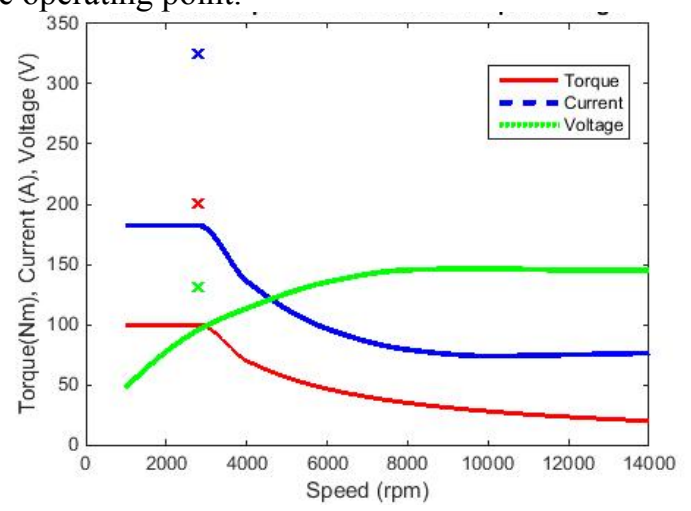

Fig. 13 - Torque speed characteristic with required VA ratings

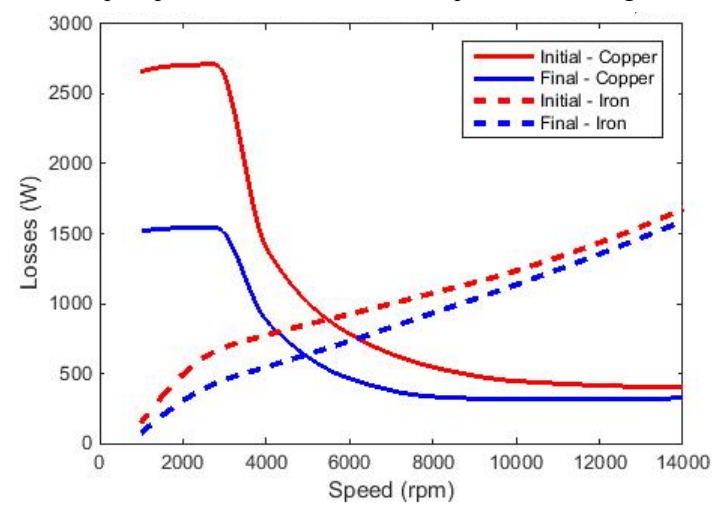

Fig. 14 -Comparison between the losses of the previous and final PMaSynRel design

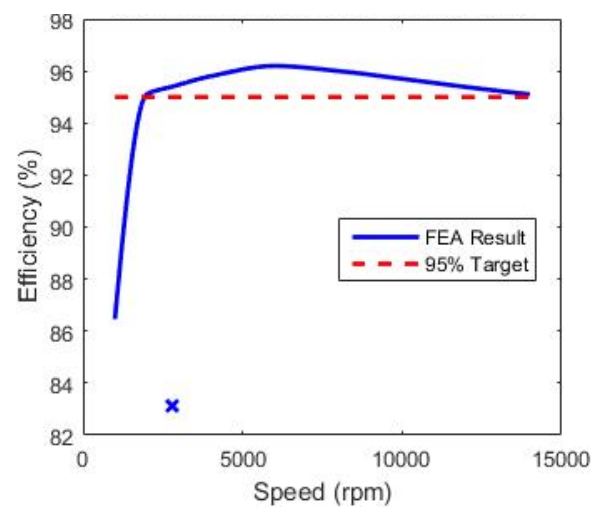

Fig. 15 - Efficiency of the final PMa-SynRel machine whilst producing the torque speed characteristic

\section{Thermal Discussion}

The two main limits for any machine include the electromagnetic and the thermal constraints [15]. Most of the above is dedicated to the magnetic limitation of the machine. However for the design procedure to be complete, a thermal analysis needs to be included. The thermal analysis is critical here, as considerably high currents densities $\left(14.7 \mathrm{~A} / \mathrm{mm}^{2}\right)$ were needed to meet the rated torque at rated speed, and even higher $\left(37.6 \mathrm{~A} / \mathrm{mm}^{2}\right)$ to reach the peak torque. From the developed thermal models of the machine, very high temperatures in the conductors were registered, with the main hot spot occurring in the end windings. To overcome this, an innovative cooling method mainly focused on thermal management of the end-windings (which of course leads to temperature reduction in the rest of the windings) was proposed and implemented. Unfortunately further details of this cooling method cannot be discussed at this time as a patent is being applied for.

Considering that the peak torque is required for a maximum of 18 seconds, the thermal management of the machine was designed around this aspect. The machine temperature was brought to a steady state value (relative to the rated torque losses) and then the losses relative to the peak torque condition were applied for a transient of 18 seconds. The resulting temperatures, with and without the innovative cooling method, are shown in Table IV, where it can be observed how the proposed thermal management technique results in excellent reductions of winding temperatures that meet the temperature requirements related to a Class $\mathrm{H}$ insulation system.

TABLE IV

THERMAL RESUlts AFTER APPLICATION OF PEAK TORQUe LOSSES

\begin{tabular}{|l|l|l|}
\hline \multirow{2}{*}{$\begin{array}{l}\text { Machine } \\
\text { Component }\end{array}$} & \multicolumn{2}{|l|}{ Hot spot Temperature $\left({ }^{\circ} \mathrm{C}\right)$} \\
\cline { 2 - 3 } Stator & 167.3 & 148.1 \\
\hline Slot Copper & 205.9 & 174.5 \\
\hline End Winding & 216.4 & 177.3 \\
\hline
\end{tabular}

The thermal management technique mentioned above has already been validated by experimental results and will be presented in a future paper, which is already in progress.

\section{FUTURE WORK}

The main limiting factor in the machine designs presented above being improved further is the thermal constraints. This is a serious issue when producing the peak torque, as the current densities are very high and thus so are the copper losses and slot temperature. As highlighted above, in order to achieve the FreedomCar 2020 targets, an innovative cooling method has been implemented, both in simulations and experimentally on an instrumented test set-up comprising of a specifically constructed section of the stator, these experimental results were then used to validate and fine tune the simulation models.

Another main challenge encountered during the development of this work is related to the high value torque ripple, synonymous with PMa-SynRel machines. As mitigation to this effect, the rotor was skewed in 5 slices. Such a measure allows the achievement of the torque ripple reduction at the cost of extra manufacturing complexity. Thus a next objective is to reduce the torque ripple by addressing directly the pre-skewing design.

The final steps are to prototype and test this machine design.

\section{CONCLUSION}

The main objective of this paper was to illustrate a comprehensive design procedure for electrical machines that are able meet the FreedomCar 2020 targets. The final design of the proposed machine is thus compared back to the targets, given in Table $\mathrm{V}$.

The minimum efficiency only considers the rated torque speed characteristic above $10 \%$ maximum speed (the specification from the targets). In this operating range, the 
efficiency requirement of $95 \%$ has been achieved. The power targets were slightly exceeded. This means that further time could be spent reducing the design volume whilst maintaining the performance requirements. The DC link voltage has only been considered as marginally met as the rated value of $325 \mathrm{~V}$ is required to maintain the performance, whilst the minimum value this could take is $200 \mathrm{~V}$. While the cost target still has not been achieved, the small amount of PM mass $(0.79 \mathrm{~kg})$ will considerably help to proceed towards this target.

Overall this paper has both detailed a comprehensive design process and presented a traction machine design which achieves all the FreedomCar 2020 targets, excluding cost. The plan going forward is to investigate the cooling required for the peak torque further and prototype this machine design. TABLE V

CONCENTRATED VS. DisTRIBUTED DESIGN

\begin{tabular}{|c|l|c|}
\hline Rated Power (kW) & 30.7 & $\checkmark$ \\
\hline Peak Power (kW) & 59.5 & $\checkmark$ \\
\hline Peak Torque (Nm) & 200.3 & $\checkmark$ \\
\hline Maximum Current (Arms) & 325 & $\checkmark$ \\
\hline DC Link Voltage (V) & 325 & - \\
\hline Max Back EMF at Max Speed (V) & 375 & $\checkmark$ \\
\hline Winding Temperature (' ${ }^{\circ}$ ) & 177.3 & $\checkmark$ \\
\hline Maximum Machine Diameter (mm) & 250 & $\checkmark$ \\
\hline Maximum Machine Length (mm) & 130 & $\checkmark$ \\
\hline Maximum Machine Volume (L) & 6.38 & $\checkmark$ \\
\hline Mass (kg) & 33.6 & $\checkmark$ \\
\hline Minimum Peak Efficiency (\%) & 95.4 & $\checkmark$ \\
\hline
\end{tabular}

IX. REFERENCES
A. M. El-Refaie, J. P. Alexander, S. Galioto, P. Reddy, H. KumKang, P. de Bock, et al., "Advanced high power-density interior permanent magnet motor for traction applications," in Energy Conversion Congress and Exposition (ECCE), 2013 IEEE, 2013, pp. 581-590.

W. L. Soong, P. B. Reddy, A. M. El-Refaie, T. M. Jahns, and N. Ertugrul, "Surface PM Machine Parameter Selection for Wide Field-Weakening Applications," in Industry Applications Conference, 2007. 42nd IAS Annual Meeting. Conference Record of the 2007 IEEE, 2007, pp. 882-889.

J. K. Tangudu and T. M. Jahns, "Comparison of interior PM machines with concentrated and distributed stator windings for traction applications," in Vehicle Power and Propulsion Conference (VPPC), 2011 IEEE, 2011, pp. 1-8.

T. Raminosoa, A. El-Refaie, P. Di, H. Kum-Kang, J. Alexander, $\mathrm{K}$. Grace, et al., "Reduced rare-earth flux switching machines for traction applications," in Energy Conversion Congress and Exposition (ECCE), 2014 IEEE, 2014, pp. 318-327.

U. S. Department of Energy, "FY 2011 Vehicle Technologies Program Wide Funding Opportunity Announcement Funding Opportunity Number: DE-FOA-0000239," ed, 2011, pp. 17-18. J. K. Tangudu, T. M. Jahns, and T. P. Bohn, "Design, analysis and loss minimization of a fractional-slot concentrated winding IPM machine for traction applications," in Energy Conversion Congress and Exposition (ECCE), 2011 IEEE, 2011, pp. 22362243.

A. Walker, M. Galea, C. Gerada, A. Mebarki, and D. Gerada, "A Topology Selection Consideration of Electrical Machines for Traction Applications: Towards the FreedomCar 2020 Targets," in Ecological Vehicles Renewable Energies (EVER), in press, Monaco 2015.

M. Galea, T. Hamiti, and C. Gerada, "Torque density improvements for high performance machines," in Electric Machines \& Drives Conference (IEMDC), 2013 IEEE International, 2013, pp. 1066-1073.
[9] A. M. El-Refaie, "Motors/Generators for Traction/Propulsion Applications: A Review," Vehicular Technology Magazine, IEEE, vol. 8, pp. 90-99, 2013.

[10] X. Wei, Z. Jianguo, G. Youguang, W. Shuhong, W. Yi, and S Zhanghai, "Survey on electrical machines in electrical vehicles," in Applied Superconductivity and Electromagnetic Devices, 2009. ASEMD 2009. International Conference on, 2009, pp. 167-170.

[11] W. Wang and B. Fahimi, "Comparative study of electric drives for EV/HEV propulsion system," in Electrical Systems for Aircraft, Railway and Ship Propulsion (ESARS), 2012, 2012, pp. $1-6$.

[12] F. Cupertino, G. M. Pellegrino, E. Armando, and C. Gerada, "A SyR and IPM machine design methodology assisted by optimization algorithms," in Energy Conversion Congress and Exposition (ECCE), 2012 IEEE, 2012, pp. 3686-3691.

[13] A. Walker, M. Galea, C. Gerada, A. Mebarki, and D. Gerada, "Design considerations for high performance traction machines: Aiming for the FreedomCar 2020 targets," in Electrical Systems for Aircraft, Railway, Ship Propulsion and Road Vehicles (ESARS), 2015 International Conference on, 2015, pp. 1-6.

[14] "MotorCAD," v9 ed: Motor Design LTD.

[15] M. Galea, C. Gerada, T. Raminosoa, and P. Wheeler, "A Thermal Improvement Technique for the Phase Windings of Electrical Machines," Industry Applications, IEEE Transactions on, vol. 48, pp. 79-87, 2012.

\section{BIOGRAPHIES}

Adam Walker (M'15) received the MEng in 'Electrical and Electronic Engineering with Mathematics' from the University of Nottingham in 2012. He is currently a Research Associate working on projects relating to electromagnetic design of electrical machines and passives with the Power Electronics, Machines and Control Group at the University of Nottingham, $\mathrm{UK}$, where he is also finishing the $\mathrm{PhD}$. His main research interests are high performance traction machines, electrical machine thermal improvements and electro-magnetic design of passive devices.

Michael Galea (M'15) received the Ph.D. degree in electrical machines design from The University of Nottingham, Nottingham, U.K., in 2013. He is currently the Deputy Director of the Institute for Aerospace Technology with The University of Nottingham. He is a Lecturer in Electrical Machines and Drives with the Department of Electrical and Electronic Engineering, The University of Nottingham. His current research interests include design, analysis, integration, and thermal management of electrical machines and drives.

David Gerada received the Ph.D. degree in high speed electrical machines from The University of Nottingham, Nottingham, U.K., in 2012. In 2007, he joined the Research and Technology Department, Cummins Generator Technologies, Stamford, U.K., as an Electromagnetic Design Engineer. His research interests include high-speed machines, traction machines, use of novel materials, and multiphysics-based optimization of electrical machines.

Chris Gerada (M'05) received the Ph.D. degree in numerical modelling of electrical machines from The University of Nottingham, Nottingham, U.K., in 2005. He was appointed as a Lecturer in Electrical Machines in 2008, an Associate Professor in 2011, and a Professor in 2013. His current research interests include the design and modelling of high performance electric drives and machines. Prof. Gerada was a recipient of the Royal Academy of Engineering Senior Research Fellowship supported by Cummins in 2011.

Abdeslam (Salem) Mebarki received the $\mathrm{Ph} . \mathrm{D}$. degree in electrical and electronic engineering from the University of Bath, Bath, U.K. In 2000, he joined the Research and Technology Department, Cummins Generator Technologies, Stamford, U.K., as an Electromagnetic Design Engineer. His research interests include electrical machine design, development, and control.

Neil L. Brown received the Ph.D. degree in electrical machines from Durham University, Durham, U.K., in 2002. Since 1995, he has been with the Research and Technology Department, Cummins Generator Technologies, Stamford, U.K., where he is currently the Director of advanced electrical machines research and technology. He is also a Visiting Professor of electrical machines with The University of Nottingham, Nottingham, U.K. He is the author of over 60 published papers and a holder of 11 patents. Dr. Brown is a Chartered Engineer in the U.K. and a Fellow of the Institution of Engineering and Technology 